\title{
Inheritance of Random Amplified Polymorphic DNA (RAPD) Markers in Theobroma cacao L.
}

\author{
C.M. Ronning ${ }^{1}$ and R.J. Schnell \\ U.S. Department of Agriculture, National Clonal Germ Plasm Repository, 13601 Old Cutler Road, Miami, \\ FL 33158
}

D.N. Kuhn

Florida International University, Department of Biological Sciences, Miami, FL 33199

Additional index words. cocoa, DNA

\begin{abstract}
RAPD markers have been used successfully in genetic analysis of several crop plants. This method poses difficulties with a highly heterozygous species such as Theobroma cacao because of the dominant phenotypic expression of bands. A backcross family derived from ctultivars Catongo and Pound 12 was analyzed to determine the efficacy of RAPD markers in analyzing cacao populations. A preliminary screen of the parents and the $F_{1}$ plant used as the backcross parent was conducted with 180 RAPD primers; of these, $26 \%$ were polymorphic and reproducible and produced 104 storable loci. Genomic DNA from 54 individuals of the backcross population was then amplified with these primers; $68.3 \%$ of the loci segregated as expected in a Mendelian fashion. Separation of RAPD fragments on acrylamide revealed an additional polymorphic locus from one primer that was indistinguishable on agarose. The results demonstrated that RAPD markers can be used to study the cacao genome.
\end{abstract}

The seed of Theobroma cacao, the cocoa bean, is a major crop in the tropics of Central and South America, Asia, and Africa. The commercial cultivars grown in these areas are derived principally from three main morphological types: Forasteros, Criollos, and Trinitarios. These types differ greatly in flavor, yield, and susceptibility to diseases such as witches' broom [Crinipellis perniciosus (Stahel) Singer], cacao swollen shoot virus, Ceratocystis wilt, pod rot (Monilia roreri Cif.), and other cankers and pod rots (Phytophthora spp.). For example, the fine-flavored Criollos lack vigor and are highly disease susceptible, the more robust Forasteros produce the bulk, or ordinary, cocoa, and the Trinitarios are highly variable (Wood and Lass, 1985).

Cacao breeding through traditional methods has been slowed by the long generation time and large multiyear field plot testing requirements. $F_{1}$ hybrids from current commercial clones, released as synthetics, resulted in seedlings with variable field performance and yields well below the midparent values for cacao (Hunter, 1990). Although much variability exists, most breeding work has used only a narrow genetic base (Wood and Lass, 1985). Improvement has focused on traits that, for the most part, are under polygenic control and have low heritabilities, such as yield and resistance to witches' broom disease. Lockwood et al. (1991) used a factorial mating design (NC Design II) to estimate genetic variation for girth, yield, and height of jorquette (low branches arising near the apex of the main 'axis). They demonstrated that most variation was additive and that heterosis was unimportant. Soria et al. (1974) also demonstrated that most important traits have low heritabilities. These results indicate that some type of cyclical selection program should be used to improve the general

Received for publication 31 Oct. 1994, Accepted for publication 8 Feb. 1995, This research was funded by a grant from the American Cocoa Research Institute (ACRI). Plant material was provided by Jorge Morera, Centro Agronómico Tropical de Investigación y Enseñanza (CATIE), Turrialba, Costa Rica, and Paul J. Fritz, Pennsylvania State Univ. -ACRI Cocoa Molecular Biology Laboratory, State College, Pa. We thank Derek Harkins, Vivian Perez, and Paul Madeira for their excellent technical assistance. The cost of publishing this paper was defrayed in part by the payment of page charges. Under postal regulations, this paper therefore must be hereby marked advertisement solely to indicate this fact. ${ }^{1}$ To whom reprint requests should be addressed. level of performance for yield (number of fruit per tree, wet or dry bean weight per fruit and per tree, weight of individual beans), disease resistance, bean quality, and growth habit. A simple halfsib family selection program in cacao would take 8 to 10 years per cycle, discouraging plant breeders from this approach. Gains have been made by crossing current commercial clones and progeny testing. Superior performing progeny have been released for clonal propagation in Malaysia and elsewhere (Chong and Sidhu, 1991; Pang Thau Yin et al., 1991), but clonal propagation is not desirable for the farmer because of the increased labor.

Marker-aided selection (MAS) can improve efficiency inbreeding for such traits, especially in early generations of selection, if molecular markers can be found that account for most of the additive genetic variance (Lande, 1992). This approach has been studied in loblolly pine (Williams and Neale, 1992). Because a suitable set of markers must be available to produce a saturated linkage map, MAS has not been evaluated in long-lived, tropical tree crops such as cacao, mango, or avocado. MAS could reduce the cycle time considerably and significantly increase gains per cycle in the first few generations, as has been demonstrated in corn (Stuber et al., 1987). Such an increase in efficiency would justify the evaluation of MAS in cacao.

Genetic diversity in cacao has been characterized using morphological descriptors (Engels et al., 1980), isozymes (Atkinson et al., 1986; Lanaud, 1986; Ronning and Schnell, 1994), restriction fragment length polymorphisms (Figuiera et al., 1992; Laurent et al., 1993), and RAPD markers (Figuiera et al., 1992; Russell et al., 1993; Wilde et al., 1992). Considerable polymorphism found with all methods significantly reflects the diversity within the species. Of these methods, RAPD offers the highest potential for generating large numbers of markers with the greatest ease (Russell et al., 1993; Welsh and McClelland, 1990; Williams et al., 1990). RAPD markers have some limitations, however, including questionable reproducibility of some bands, a requirement for stringent standardization of reaction conditions, comigration of different amplification products, and dominant inheritance (Bachmann, 1994). Factors other than heredity, such as repetitive DNA and genome size, may account for pattern variation (Bachmann, 1994); novel bands arising in offspring of known pedigree have been reported 
in primates (Riedy et al., 1992). Therefore, the Mendelian inheritance of these markers must be demonstrated. Each locus must be examined individually for reliability in genetic studies. Such markers can then be used in genome mapping.

\section{Materials and Methods}

Plant materials. The backcross population was derived from a 'Catongo' $\mathrm{x}$ 'Pound 12' cross, with 'Catongo' as the recurrent parent (Morera et al., 1991). Both cultivars are Forastero types. 'Catongo' is indigenous to Brazil, while 'Pound 12' is a selection made by F.J. Pound from the Amazon region of Peru (Pound, 1943). 'Pound 12' is self-incompatible and, therefore, highly heterozygous. 'Catongo' is self-compatible and at least partially inbred, as evidenced by the fact that 'Catongo' breeds true for the recessive white-seeded character. This family is located at the Centro Agronómico Tropical de Investigación y Enseñanza

Table 1. Scheme used to score RAPD fragments and to determine expected segregation ratios in the backcross progeny of a 'Catongo' $\mathrm{x}$ 'Pound 12' cross ( 1 = band present; $0=$ band absent $)$. 'Catongo' was used as the female recurrent parent in the cross; 'Pound 12' was used as the male (Morera et rd., 1991).

\begin{tabular}{lccc}
\hline \hline 'Catongo' & $\mathrm{F}_{1}$ & 'Pound 12' & $\begin{array}{c}\text { Expected segregation } \\
\text { in } \mathrm{BC}_{1}\end{array}$ \\
\hline 1 & 1 & 1 & All 1 or $3: 1$ \\
1 & 1 & 0 & All 1 or $3: 1$ \\
1 & 0 & 1 & $1: 1$ \\
1 & 0 & 0 & $1: 1$ \\
0 & 1 & 1 & $1: 1$ \\
0 & 0 & 1 & All 0
\end{tabular}

(CATIE) in Turrialba, Costa Rica. The parents, the $\mathrm{F}_{1}$ plant used as the male parent of the backcross, and 54 randomly selected trees from the backcross $\left(\mathrm{BC}_{1}\right)$ progeny were analyzed. Parental, $\mathrm{F}_{1}$, and eight $\mathrm{BC}_{1}$ trees were resampled two or three times to test reproducibility.

DNA extraction. DNA was extracted and purified from 1 to $6 \mathrm{~g}$ fresh weight $(\mathrm{FW})$ of leaf tissue following methods previously described (Couch and Fritz, 1990; Figuiera et al., 1992), with modifications. Leaf tissue was ground to a fine powder in liquid nitrogen, and then $10 \mathrm{ml} \cdot \mathrm{g}^{-1}$ fresh weight extraction buffer consisting of $50 \mathrm{~mm}$ Tris- $\mathrm{HCl}$ ( $\mathrm{pH} 8.0$ ), $5 \mathrm{mM} \mathrm{MgCl}_{2}, 0.3 \mathrm{M}$ sucrose, 0.1 $\mathrm{M}$ diethyldithiocarbamic acid (DEDTC), and 2\% (w/v) polyvinylpyrrolidone (PVP-40) was added. The homogenate was filtered through four layers of cheesecloth and two layers of Miracloth into a clean 50-ml centrifuge tube. The filtrate was centrifuged at 600 to $1000 \mathrm{X}$ g for $15 \mathrm{~min}$ at $4 \mathrm{C}$. The nuclear pellets were resuspended in 0.5 to $1.0 \mathrm{ml}$ extraction buffer, and an equal amount of lysis buffer [100 mm Tris- $\mathrm{HCl}(\mathrm{pH} 8.0), 40 \mathrm{~mm}$ ethylenediaminetetrmcetic acid (EDTA), and 270 (w/v) sarkosyl] was added. For each sample, $3.12 \mathrm{~g}$ of cesium chloride $(\mathrm{CSCl})$ was dissolved in $2 \mathrm{ml}$ of $10 \mathrm{~mm}$ Tris- $\mathrm{HCl}(\mathrm{pH} \mathrm{7.4)}$ and $1 \mathrm{~mm}$ EDTA (TE), then $125 \mu \mathrm{l} \cdot \mathrm{g}^{-1}$ fresh weight ethidium bromide $\left(10 \mathrm{mg} \cdot \mathrm{ml}^{-1}\right)$ was added. The nuclei suspension was added to this solution and gently mixed, then centrifuged at $10,000 \times \mathrm{g}$ for $10 \mathrm{~min}$ at room temperature to remove insoluble material. The refractive index was adjusted between 1.3860 to 1.3865 , and samples were centrifuged at $340,000 \times \mathrm{g}, 20 \mathrm{C}$, for $6 \mathrm{~h}$. The DNA band extracted from the $\mathrm{CsCl}$ gradient was dialyzed against $\mathrm{TE}(\mathrm{pH} \mathrm{7.4)}$ ) for 12 to $24 \mathrm{~h}$, with at least one change of buffer. Samples were concentrated by precipitation in EtOH-NaOAc and dissolved in $\mathrm{TE}(\mathrm{pH} 7.4)$. Crude extracts obtained using simpler procedures (CTAB, SDS) yielded sufficient amounts of DNA, but produced inconsistent results from subsequent amplifications.

\section{A}

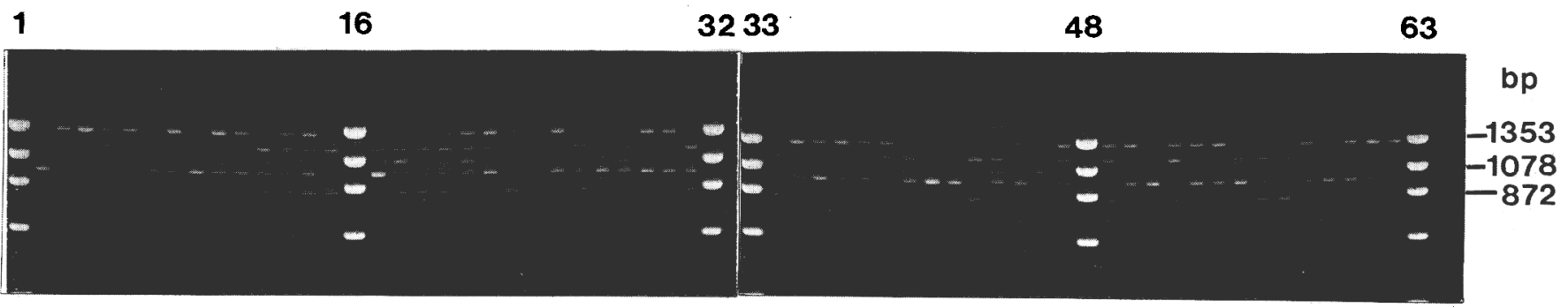

B

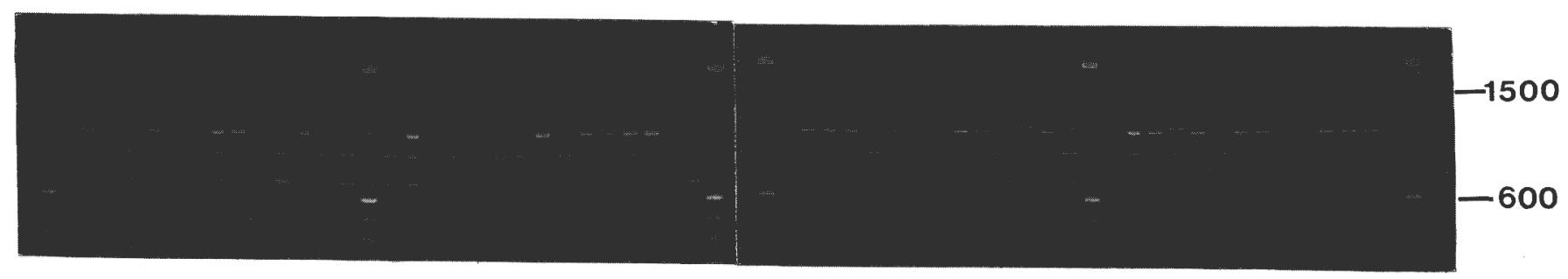

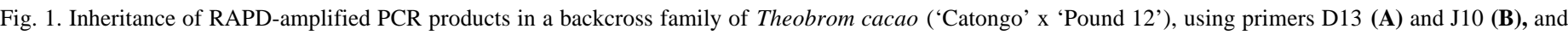

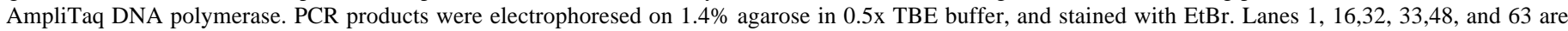
molecular size markers; lane 2 is 'Catongo;' lane 3 is $\mathrm{F}_{1}$; lane 4 is 'Pound 12; lanes 5-15, 17-31, 34-47, and 49-62 are BC progeny; lane 64 is negative control. Markers are $\phi$ X174/HaeIII in A, 100-bp ladder (Gibco BRL; Gaithersburg, Md.) in B. 


\begin{tabular}{|c|c|c|c|c|c|c|}
\hline \multirow[b]{2}{*}{ Locus } & & \multirow[b]{2}{*}{ Enzyme $^{2}$} & & \multicolumn{2}{|c|}{ Segregation in $\mathrm{BC}_{1}$} & \multirow[b]{2}{*}{$\chi^{2}$} \\
\hline & & & & Observed & Expected & \\
\hline A15-780 & & A & & $33: 21$ & $27: 27(1: 1)$ & 2.667 \\
\hline A16-1170 & & $\mathbf{A}$ & & $42: 7$ & $36.7: 12.2(3: 1)$ & 3.000 \\
\hline A16-1600 & & $\mathrm{SF}$ & - & $24: 29$ & $26.5: 26.5(1: 1)$ & 0.472 \\
\hline Al7-850 & & SF & & $0: 52$ & $0: 52$ (all 0) & $--^{y}$ \\
\hline A19-320 & & SF & & $54: 0$ & 54:0 (all 1) & --- \\
\hline A $19-520$ & & SF & & $35: 19$ & $40.5: 13.5(3: 1)$ & 2.988 \\
\hline A19-570 & & SF & & $25: 29$ & $27: 27(1: 1)$ & 0.296 \\
\hline B1-800 & & $\mathrm{SF}$ & & $26: 28$ & $27: 27(1: 1)$ & 0.074 \\
\hline B5-370 & & $\mathrm{SF}$ & & $27: 27$ & $27: 27(1: 1)$ & 0 \\
\hline B5-1300 & & SF & & $29: 25$ & $27: 27(1: 1)$ & 0.296 \\
\hline B6-1070 & & $\mathrm{A}$ & & $20: 33$ & $26.5: 26.5(1: 1)$ & 3.189 \\
\hline B8-590 & & SF & & $27: 26$ & $26.5: 26.5(1: 1)$ & 0.019 \\
\hline B8-910 & & SF & & $54: 0$ & $54: 0$ (all 1) & --- \\
\hline B11-500 & & A & & $28: 24$ & $26: 26(1: 1)$ & 0.308 \\
\hline B11-1180 & & A & & $53: 1$ & $54: 0($ all 1$)$ & --- \\
\hline B11-1800 & & A & & $22: 32$ & $27: 27(1: 1)$ & 1.852 \\
\hline B11-2100 & & A & & $37: 17$ & $40.5: 13.5(3: 1)$ & 1.210 \\
\hline B12-350 & & SF & & $53: 0$ & $53: 0($ all 1$)$ & --- \\
\hline B12-1300 & & SF & & $31: 22$ & $26.5: 26.5(1: 1)$ & 1.528 \\
\hline $\mathrm{C} 1-570$ & & SF & & $52: 2$ & $54: 0$ (all 1) & -- \\
\hline C1-720 & & $\mathrm{SF}$ & & $0: 54$ & $0: 54$ (all 0 ) & $\cdots$ \\
\hline$C 1-860$ & & SF & & $27: 27$ & $27: 27(1: 1)$ & 0 \\
\hline C3-710 & & SF & & $54: 0$ & $54: 0$ (all 1) & --- \\
\hline C3-950 & & SF & & $28: 26$ & $27: 27(1: 1)$ & 0.074 \\
\hline C3-1000 & & SF & & $0: 54$ & $0: 54$ (all 0) & $\ldots$ \\
\hline C4-1260 & & A & & $29: 25$ & $27: 27(1: 1)$ & 0.296 \\
\hline C5-1500 & & A & & $31: 23$ & $27: 27(1: 1)$ & 1.185 \\
\hline$C 5-1600$ & . & A & & $26: 27$ & $26.5: 26.5(1: 1)$ & 0.019 \\
\hline C $8-1310$ & & SF & & $33: 19$ & $39: 13(3: 1)$ & 3.692 \\
\hline $\mathrm{C} 12-1700$ & & A & & $28: 25$ & $26.5: 26.5(1: 1)$ & 0.170 \\
\hline C15-430 & & SF & & $24: 29$ & $26.5: 26.5(1: 1)$ & 0.472 \\
\hline C15-590 & & SF & & $29: 24$ & $26.5: 26.5(1: 1)$ & 0.472 \\
\hline C15-600 & & SF & & $29: 24$ & $26.5: 26.5(1: 1)$ & 0.472 \\
\hline D1-390 & & SF & & $33: 20$ & $26.5: 26.5(1: 1)$ & 3.189 \\
\hline D1-1700 & & SF & & $28: 26$ & $27: 27(1: 1)$ & 0.074 \\
\hline D3-1180 & & SF & & $53: 0$ & $53: 0$ (all 1 ) & -- \\
\hline D3-1300 & & SF & & $36: 16$ & $39: 13(3: 1)$ & 0.923 \\
\hline D13-840 & & A & & $28: 26$ & $27: 27(1: 1)$ & 0.074 \\
\hline D13-1050 & & A & & $26: 28$ & $27: 27(1: 1)$ & 0.074 \\
\hline D13-1320 & & A & & $29: 25$ & $27: 27(1: 1)$ & 0.296 \\
\hline E1-650 & & SF & & $31: 23$ & $27: 27(1: 1)$ & 1.185 \\
\hline E1-900 & & SF & & $28: 26$ & $27: 27(1: 1)$ & 0.074 \\
\hline E3-600 & & A & & $51: 0$ & $51: 0($ all 1$)$ & --- \\
\hline E5-550 & & SF & & $54: 0$ & $54: 0$ (all 1) & --- \\
\hline E5-1030 & & SF & & $27: 27$ & $27: 27(1: 1)$ & 0 \\
\hline E11-1000 & & A & & $40: 9$ & $36.7: 12.2(3: 1)$ & 1.150 \\
\hline E18-700 & & A & & $0: 48$ & $0: 48$ (all 0) & --- \\
\hline E19-1400 & & A & & $46: 8$ & $40.5: 13.5(3: 1)$ & 2.988 \\
\hline E19-1450 & & A & & $25: 29$ & $27: 27(1: 1)$ & 0.296 \\
\hline F2-1060 & & A & & $30: 24$ & $27: 27(1: 1)$ & 0.667 \\
\hline F8-430 & & SF & & $27: 25$ & $26: 26(1: 1)$ & 0.170 \\
\hline F8-800 & $\rightarrow$ & SF & & $28: 25$ & $26.5: 26.5(1: 1)$ & 0.170 \\
\hline F9-1550 & & A & & $44: 10$ & $40.5: 13.5(3: 1)$ & 1.210 \\
\hline F9-1650 & & A & & $44: 10$ & $40.5: 13.5(3: 1)$ & 1.210 \\
\hline F9-1800 & & A & & $23: 30$ & $26.5: 26.5(1: 1)$ & 0.924 \\
\hline F13-780 & & $A$ & & $22: 32$ & $27: 27(1: 1)$ & 1.852 \\
\hline F16-950 & & A & & $41: 6$ & $35.2: 11.7(3: 1)$ & 3.752 \\
\hline F20-1480 & & A & & $29: 25$ & $27: 27(1: 1)$ & 0.296 \\
\hline F20-1900 & & A & & $54: 0$ & $54: 0$ (all 1) & --- \\
\hline H9-320 & & $\mathrm{SF}$ & & $27: 26$ & $26.5: 26.5(1: 1)$ & 0.019 \\
\hline H15-1200f & & A & & $54: 0$ & $54: 0$ (all 1) & +- \\
\hline $\mathrm{H} 15-1200 \mathrm{~m}$ & & A & & $29: 25$ & $27: 27(1: 1)$ & 0.296 \\
\hline $\mathrm{H} 15-1200 \mathrm{~s}$ & & A & & $0: 54$ & $0: 54$ (all 0) & --- \\
\hline H15-1230f & & A & & $0: 54$ & $0: 54$ (all 0) & -- \\
\hline H15-1230s & & A & & $0: 54$ & $0: 54$ (all 0) & --- \\
\hline I1 -820 & & A & + & $26: 28$ & $27: 27(1: 1)$ & 0.074 \\
\hline I11-1100 & & A & & $0: 51$ & $0: 51$ (all 0 ) & --- \\
\hline J5-840 & & A & & $30: 24$ & $27: 27(1: 1)$ & 0.667 \\
\hline $\mathrm{J} 10-1060$ & & $\mathrm{~A}$ & & $34: 20$ & $27: 27(1: 1)$ & 3.63 \\
\hline $\mathrm{J} 101150$ & & A & & $33: 21$ & $27: 27(1: 1)$ & 2.667 \\
\hline $\mathrm{J} 19-680$ & & A & & $26: 28$ & $27: 27(1: 1)$ & 0.074 \\
\hline
\end{tabular}

${ }^{2}$ Type of Taq DNA polymerase used to produce band: A = AmpliTaq, whole enzyme; SF = Stoffel fragment of AmpliTaq. ${ }^{y}$ Not computable. 


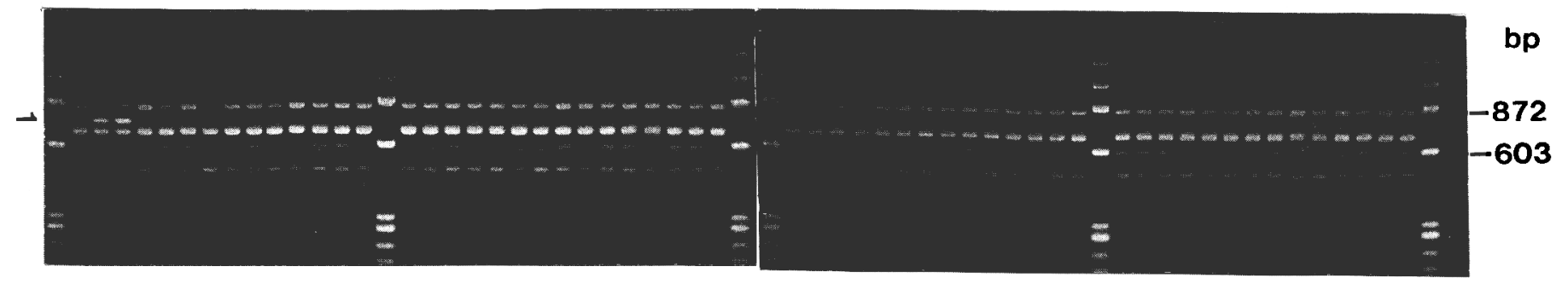

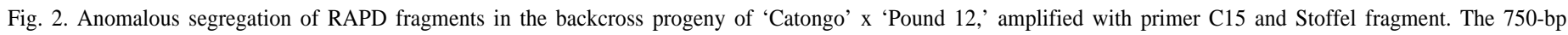
fragment, present in 'Pound 12' and the $\mathrm{F}_{1}$ but absent elsewhere, is indicated by arrow on left. PCR products were electrophoresed on $2 \%$ agarose in $0.5 \mathrm{x}$ TBE buffer and stained with EtBr. Lane designations as in Fig. 1. Size marker is $\phi$ X174/HaeIII.

Amplification. Genomic DNA was amplified with AmpliTaq DNA polymerase (Perkin Elmer; Norwalk, Corm.) or AmpliTaq DNA polymerase, Stoffel fragment (Perkin Elmer). The AmpliTaq PCR reaction contained $50 \mathrm{~mm} \mathrm{KCl,} 10 \mathrm{~mm}$ Tris- $\mathrm{HCl}$ (pH 8.3), 2.5 $\mathrm{mM} \mathrm{MgCl}, 0.1 \mathrm{~mm}$ each dATP, dCTP, dGTP, and dTTP, $0.02 \mathrm{U} /$ $\mu \mathrm{l}$ AmpliTaq, $0.2 \mu \mathrm{M}$ primer (Operon Technologies; Alameda, Calif.), and $0.4 \mathrm{ng} \cdot \mu^{-1}{ }^{-1}$ genomic DNA. The Stoffel PCR reaction consisted of $10 \mathrm{~mm} \mathrm{KC1}, 10 \mathrm{~mm}$ Tris- $\mathrm{HCl}$ ( $\mathrm{pH} 8.3$ ), $4.0 \mathrm{mM} \mathrm{MgCl}_{2}$, $0.1 \mathrm{~mm}$ each dATP, dCTP, dGTP, and dTTP, 0.1 U/ $\mu$ l Stoffel fragment, $0.4 \mu \mathrm{M}$ primer (Operon), and $0.4 \mathrm{ng} . \mu \mathrm{l}^{-1}$ genomic DNA. Both reactions were performed in a total volume of $25 \mu \mathrm{l}$ overlayed with mineral oil. The reactions were either run immediately, or the reaction mixtures were stored at $0 \mathrm{C}$ and used within 1 week. DNA was amplified in a DNA thermal cycler (model 480; Perkin Elmer), preheated to $94 \mathrm{C}$; reactions were incubated at $94 \mathrm{C}$ for $2 \mathrm{~min}$, then run through 45 cycles of $94 \mathrm{C}$ for 15 see, $37 \mathrm{C}$ for 30 see, and $72 \mathrm{C}$ for 1 rein, followed by a final 5 min extension at 72C. Amplification products were separated on either $1.4 \%$ (AmpliTaq) or $2.0 \%$ (Stoffel) agarose gels in $0.5 \mathrm{x}$ TEE buffer [0.045 M, $0.001 \mathrm{M}$ EDTA], and visualized by ethidium bromide staining. Also, to clarify the banding patterns obtained from agarose, samples amplified with primer $\mathrm{H} 15$ were electrophoresed on $3.5 \%$ polyacrylamide gels in 1x TBE buffer and stained with ethidium bromide.

Primerscreening. One hundred-eighty RAPD primers (Operon Technologies, kits A-F, H-J) were screened initially in triplicate with the parents ('Catongo' and 'Pound 12') and the $\mathrm{F}_{1}$ individual, using AmpliTaq DNA polymerase, Stoffel fragment, or both. Primers that produced reproducible, polymorphic bands were used to amplify the $\mathrm{BC}_{1}$ population. Loci were scored as $\mathrm{O}$ (band absent) or 1 (band present), and marker loci were designated by the primer used, followed by the fragment size in base pairs. All reproducible bands were scored. The $\mathrm{BC}_{1}$ progeny were amplified at least twice with each suitable primer to verify patterns and reproducibility.

Analysis. Expected ratios in the $\mathrm{BC}_{1}$ were determined from the RAPD phenotypes of the parents and the $\mathrm{F}_{1}$ individual used as the male parent to generate the backcross (Table 1). Chi-square analysis to test goodness of fit of observed ratios was performed using a probability level of 0.05 .

\section{Results}

The Stoffel fragment of AmpliTaq DNA polymerase produced more and smaller bands than the whole enzyme. While many primers did not produce any amplification products with the whole enzyme, Stoffel fragment was often successful. We collected more information from the same group of primers by using both types of enzyme.

Of the 180 primers, 47 (26\%) produced reproducible, polymor- phic bands after the initial primer screening of the parents and $F_{1}$. One hundred four such loci were identified; the number of storable loci for each primer ranged from 1 to 7 . Seventy-one loci $(68.3 \%)$ segregated acceptably close to the expected ratios of $3: 1,1: 1$, all present, or all absent (Fig. 1, Table 2). Thirty-three loci (31.7\%) had anomalous ratios in the $\mathrm{BC}_{1}$ that could not be explained by Mendelian inheritance. Primer C 15 and Stoffel fragment producdd strong bands at $750 \mathrm{bp}$ in 'Pound 12' and the $\mathrm{F}_{1}$ (Fig. 2). While a $1: 1$ segregation was expected in the $\mathrm{BC}_{1}$ from this parental configuration, the band was absent in all 54 progeny.

Primer H15 produced three bands on agarose (Fig. 3A). A 1230bp band appearing in 'Pound 12' and absent in 'Catongo' appeared to shift to $1250 \mathrm{bp}$ in the $\mathrm{F}_{\mathrm{l}}$; this 1250 -bp band segregated $1: 1$ in the $\mathrm{BC}_{1}\left(x^{2}=0.296\right)$. A 1200 -bp band, which was monomorphic on agarose, was found to be composed of three separate bands when the products were electrophoresed on acrylamide (Fig. 3B). The lower band, present in 'Catongo' and the $\mathrm{F}_{1}$ and absent in 'Pound 12,' was present in all of the $\mathrm{BC}_{1}$ progeny. The middle band, present in 'Pound 12' and the $\mathrm{F}_{1}$ and absent in 'Catongo,' segregated $1: 1$ in the $\mathrm{BC}_{1}$ population, as expected. Also, a larger band was present in 'Pound 12' only; this locus is presumably heterozygous. The band at $1230 \mathrm{bp}$ in 'Pound 12' separated into two distinct bands on acrylamide, neither of which appeared in the other individuals. The 1250-bp band remained single on acrylamide.

\section{Discussion}

Cacao is a diploid $(\mathrm{n}=10)$ species (Davie, 1933; Glicenstein and Fritz, 1989). Resultant bands would therefore be expected to follow basic patterns of Mendelian inheritance. Most of the scored loci segregated as expected; however, 33 loci produced patterns that could not be explained by simple inheritance. Figures 2 and 3 show loci with highly unusual segregation patterns of very strong bands. Contamination is not likely, given the high repeatability of patterns and control results. Artifactual bands maybe produced by polymerase slippage and in vitro recombination (Jansen and Ledley, 1990). Another possible cause of anomalous segregation is genomic mutation; however, the high rate of unexpected ratios $(32 \%)$ makes this extremely remote. The possibility of plant misidentification was considered; however, evidence indicates that this is highly unlikely. If leaves of a particular individual or individuals were harvested in error, a pattern should be seen in the data indicating these individuals as outliers; no such pattern was found. It is unlikely that any of the $\mathrm{BC}_{1}$ progeny are the result of a self-fertilization of the maternal parent, 'Catongo.' If this were the case, a band present in 'Pound 12' and the $\mathrm{F}_{1}$ and absent in 'Catongo' would also be absent in the $\mathrm{BC}_{1}$ individual at every locus bearing this parental configuration; no such individual was found. 
Eight loci with anomalous segregation ratios were borderline, i.e., by accepting a higher probability level $\left(x_{1.01}^{2}=6.635\right)$, these would be considered as segregating normally. Twelve anomalous loci, including ten not considered as borderline cases described above, have segregation ratios that would fit a corrtig!-sting, two-locus model; that is, the ratios fit $15: 1$ or $7: 1$ rather than all 1 or $3: 1$ as expected, or $3: 1$ rather than the expected 1:1. Finally, the 37 loci segregating 1:1 as expected from a testcross situation, together with the flower color locus, formed 10 linkage groups, with three RAPD loci unlinked.

Two loci were noted-B 11-1180 and Cl-570-in which no segregation was expected, but ratios of 53:1 and 52:2, respectively, were observed (Table 2 ). It is possible that these two ratios actually fit 15:1 for the comigrating two-locus model discussed above. However, with a sample size of 54, this hypothesis cannot be tested. With the available data, we assume that, in these three individuals, some structural, or nongenetic, changes in the DNA at those particular sites prevented amplification. Therefore, these loci were included in the group that segregates as expected. For future studies, it would be wise to sample more individuals from the backcross population so that a proper statistical test of these ratios can be conducted.

One assumption underlying analysis of RAPD markers is that
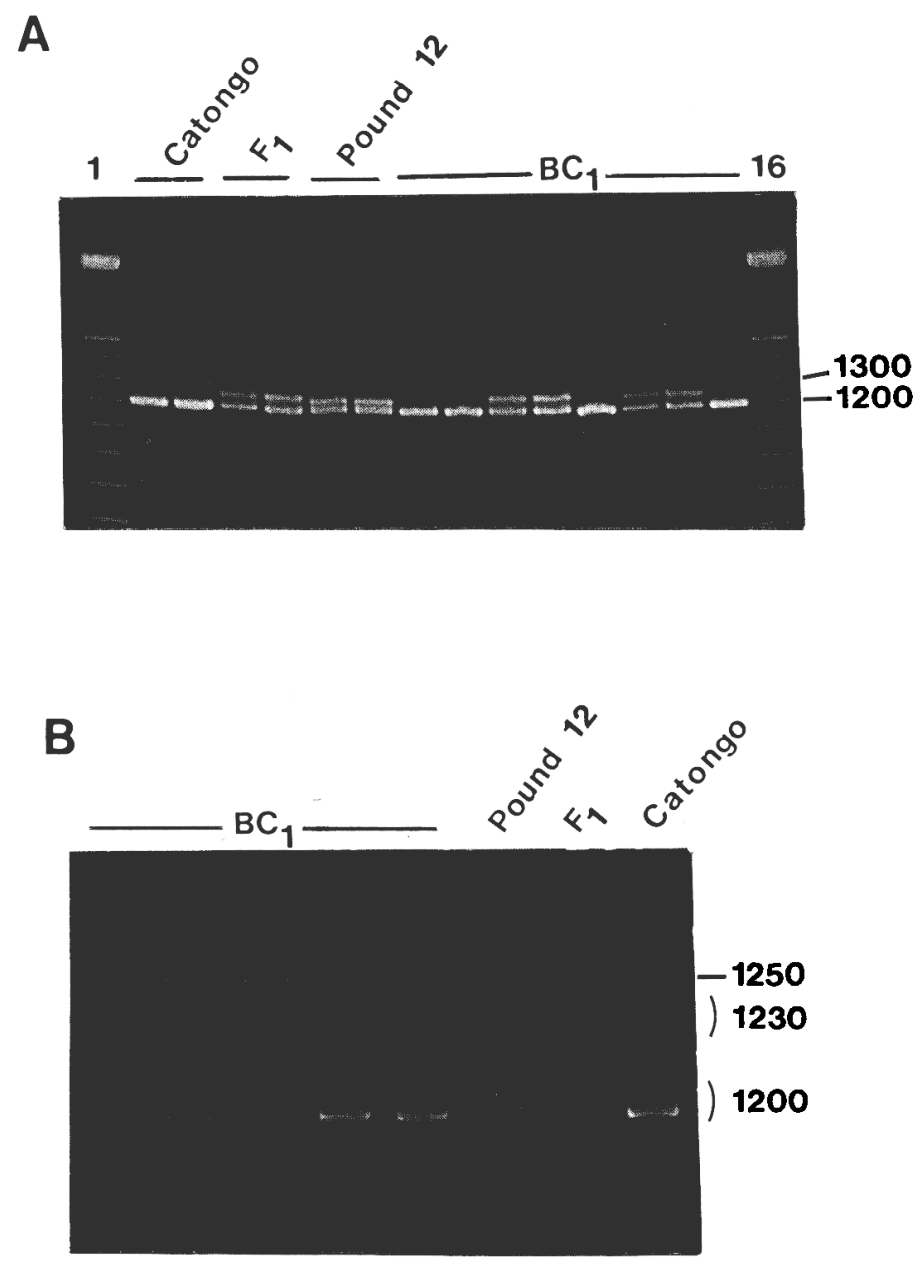

Fig. 3. Banding patterns produced by primer H15 and AmpliTaq DNA polymerase. (A) PCR products electrophoresed on $1.4 \%$ agarose in $0.5 \mathrm{x}$ TBE, stained with EtBr. Lanes 1 and 16 are 100-bp ladder lanes 2 and 3 are 'Catongo;' lanes 4 and 5 are $\mathrm{F}$,; lanes 6 and 7 are 'Pound 12' lanes 8-15 are BC $_{1}$ progeny. (B) PCR products electrophoresed on $3.5 \%$ acrylamide in $1 \mathrm{x}$ TBE, stained with EtBr. Lanes $1-5$ are $\mathrm{BC}_{1}$ progeny; lane 6 is 'Pound 12;' lane 7 is $\mathrm{F}$,; lane 8 is 'Catongo.' a single band represents a single locus. Figure 3 clearly shows that this assumption is not necessarily valid, and may explain at least some of the anomalous ratios we encountered. This finding could have serious implications for studies of genetic diversity, phylogenetics, and mapping. Assuming one band = one genetic locus in a randomly sampled, unrelated population could cause significant error in the estimation of gene diversity statistics and phylogenies. Germplasm repositories should contain as much genetic diversity as possible with the least amount of duplication; errors in fingerprinting may result in the underestimation of genetic diversity and hence the elimination of desirable genotypes from the collection. Thus, it is desirable to screen a known full-sib family and examine each locus to ensure expected inheritance patterns. By using gels of higher resolution (i.e., acrylamide rather than agarose), such errors can be minimized or avoided. In addition, it maybe possible to obtain more information from RAPD loci that appear monomorphic on agarose.

Acrylamide gel electrophoresis did not explain the shift in the 1230-1250-bp bands of primer H15 (Fig. 3). The 1230-bp band, found only in 'Pound 12,' separated into two presumably heterozygous bands. The 1250-bp band found in the $\mathrm{F}_{1}$ and half of the $\mathrm{BC}_{1}$ progeny appears to have arisen de novo. This band segregates $1: 1$ in the $\mathrm{BC}_{1}$ progeny $\left(\mathrm{x}^{2}=0.296\right)$ and shows a complete correlation with the segregation of the H15-1200m band.

Sufficient information can be obtained from a backcross population to infer the genotype of the parents from the segregation ratios of the progeny, in spite of the dominant inheritance of RAPD markers. Carlson et al. (1991) demonstrated the utility of RAPD markers in mapping various conifer genomes using $\mathrm{F}_{1}$ populations. In most cases in our study, the genotypes of the parents could be inferred from the phenotypic ratios of the $\mathrm{BC}_{1}$ (Table 1). For example, if 'Catongo' and the $\mathrm{F}_{1}$ were scored as 1 (presence), while 'Pound 12' was 0 (absence), the resulting $\mathrm{BC}_{1}$ progeny would be expected to either segregate 3:1 (if 'Catongo' and the $\mathrm{F}_{1}$ are heterozygous), or all have the band (if 'Catongo' is homozygous dominant). If the band is present in all three parental individuals, one would expect either a 3:1 ratio, or all present, but several parental genotypic states could give rise to either of these configurations. Also, a testcross (absent in 'Catongo,' present in 'Pound 12 ' and $\mathrm{F}_{1}$ ) would imply homozygous recessivity in 'Catongo,' while the state of 'Pound 12' could not be determined. Zygosity of the parents could be directly inferred from all other possible combinations of parents and $F_{1}$.

Notwithstanding the limitations, RAPD markers have proven to be a highly effective and efficient method for the genetic analysis of Theobroma cacao and other heterozygous species. With proper attention and study, RAPD markers can be very useful for estimating genetic diversity and for genome mapping.

\section{Literature Cited}

Atkinson, M.D., L.A. Withers, and M.J.A. Simpson. 1986. Characterisation of cacao germplasm using isoenzyme markers. 1. A preliminary survey of diversity using starch gel electrophoresis and standardisation of the procedure. Euphytica 35:741-750.

Bachmann, K. 1994. Tansley review no. 63: Molecular markers in plant ecology. New Phytol. 126:403-418.

Carlson, J.E., L.K. Tulsieram, J.C. Glaubitz, V.W.K. Luk, C. Kauffeldt, and R. Rutledge. 1991. Segregation of random amplified DNA markers in $F_{1}$ progeny of conifers. Theor. Appl. Genet. 83:194-200.

Chong, C.G. and M. Sidhu. 1991. Performances of PBC clones in peninsular Malaysia and Sabah. Intl. Cocoa Conf.: Challenges in the 90s, Kurds Lumpur, Malaysia, 25-28 Sept. 1991. (Abstr.)

Couch, J.A. and P.J. Fritz. 1990. Isolation of DNA from plants high in polyphenolics. Plant Molec. Biol. Rpt. 8:8-12. 
Davie, J.H. 1933. Cytological studies in the Malvaceae and certain related families. J. Genet. 28:33-67.

Engels, J. M. M., B.G.C. Bartley, and G.A. Enriquez. 1980. Cacao descriptors, their states, and modus operandi. Turrialba 30:209-218.

Figuiera, A., J. Janick, and P. Goldsbrough. 1992. Genome size and DNA polymorphism in Theobroma cacao. J. Amer. Soc. Hort. Sci. 117:673677.

Glicenstein, L.J. and P.J. Fritz. 1989. Ploidy level in Theobroma cacao L. J. Hered. 80:464-467.

Hunter, J.R. 1990. The status of cacao (Theobroma cacao, Sterculiaceae) in the Western Hemisphere. Econ. Bet. 44:425-439.

Jansen, R. and F.D. Ledley. 1990. Disruption of phase during PCR amplification and cloning of heterozygous target sequences. Nucleic Acids Res. 18:5153-5 156.

Lanaud, C. 1986. Utilisation des marqueurs enzymatiques pour l'étude génétique du cacaoyer: Theobroma cacao L. I. Contrôle génétique et "linkage" de neuf marqueurs enzymatiques. Café Cacao Thé 30:259-267.

Lande, R. 1992. Marker-assisted selection in relation to traditional methods of plant breeding, p. 437451. In: H.T. Stalker and J.P. Murphy (eds.). Plant breeding in the 1990s. C.A.B Intl., Wallingford, U.K.

Laurent, V., A-M. Risterucci, and C. Lanaud. 1993. Variability for nuclear ribosomal genes within Theobroma cacao. Heredity 71:96-103.

Lockwood, G., J. Pang Thau Yin, and A. Theng Leng. 1991. Breeding values of upper Amazon cocoa clones. Intl. Cocoa Conf.: Challenges in the 90s, Kuala Lumpur, Malaysia, 25-28 Sept. 1991. (Abstr.)

Morera, J., A. Paredes, and A. Mora. 1991. Germoplasma de cacao en el CATIE entre 1947 y 1991. Instituto Interamericano de Cooperación para la Agricultura, Coronado, Costa Rica.

Pang Thau Yin, J., D.H.K. Lim, and G. Lockwood. 1991. Clonal cocoa trials and selection for superior clones. Intl. Cocoa Conf.: Challenges in the 90s, Kuala Lumpur, Malaysia, 25-28 Sept. 1991. (Abstr.)

Pound, F.J. 1943. Cacao and witches' broom disease (Marasmius pernicious). In: H. Toxopeus (ed.). Arch. Cocoa Res. 1:73-92.

Riedy, M. F., W.J. Hamilton, III, and C.F. Aqadro. 1992. Excess of nonparental bands in offspring from known primate pedigrees assayed using RAPD PCR. Nucleic Acids Res. 20:918.

Ronning, C.M. and R.J. Schnell. 1994. Allozyme diversity in a collection of Theobroma cacao L. J. Hered. 85:291-295.

Russell, J. R., F. Hosein, E. Johnson, R. Waugh, and W. Powell. 1993. Genetic differentiation of cocoa (Theobroma cacao L.) populations revealed by RAPD analysis. Molec. Ecol. 2:89-97.

Soria, V. J., F. Ocampo, and G. Paez. 1974. Parental influence of some cacao clones on the yield performance of their progenies. Turrialba (Costa Rica) 24:58-65.

Stuber, C.W., M.D. Edwards, and J.F. Wendel. 1987. Molecular markerfacilitated investigations of quantitative trait loci in maize. II. Factors influencing yield and its component traits. Crop Sci. 27:639-648.

Welsh, J. and M. McClelland. 1990. Fingerprinting genomes using PCR with arbitrary primers. Nucleic Acids Res. 18:72 13-7218.

Wilde, J., R. Waugh, and W. Powell. 1992. Genetic fingerprinting of Theobroma clones using randomly amplified polymorphic DNA markers. Theor. Appl. Genet. 83:871-877.

Williams, C.G. and D.B. Neale. 1992. Conifer wood quality and markeraided selection: A case study. Can. J. For. Res. 22: 1009-1017.

Williams, J. G. K., A.R. Kubelik, K.J. Livak, J.A. Rafalski, and S.V. Tingey. 1990. DNA polymorphisms amplified by arbitrary primers are useful as genetic markers. Nucleic Acids Res. 18:6531-6535.

Wood, G.A.R. and R.A. Lass. 1985. Cocoa. 4th ed. Longman, New York. 